\title{
Radiomorphometric of the Jaw for Gender Prediction: A Digital Panoramic Study
}

\author{
Eha Renwi Astuti, DDS, MSc, PhD, OMR, ${ }^{1}$ Hanna Bachtiar Iskandar, DDS, PhD, OMR, ${ }^{2}$ \\ Haris Nasutianto, DDS, MSc, PhD, OMR, ${ }^{3}$ Berty Pramatika, DDS, OMR, ${ }^{4}$ \\ Deny Saputra, DDS, MSc ${ }^{1}$ and Ramadhan Hardani Putra, DDS, $\mathrm{MSc}^{1}$ \\ ${ }^{1}$ Department of Dental Maxillofacial Radiology, Faculty of Dental Medicine, Universitas Airlangga \\ ${ }^{2}$ Department of Dental Maxillofacial Radiology, Faculty of Dentistry, Universitas Indonesia \\ ${ }^{3}$ Department of Dental Maxillofacial Radiology, Faculty of Dentistry, Mahasaraswati University \\ ${ }^{4}$ Radiology Department, Universitas Brawijaya Hospital
}

\begin{abstract}
Background. Gender identification by using skeletal identification is an important tool in forensic, medico-legal, bioarkeology, and anthropology. Traditional morphological methods depended on the anthropologist subjectivity that caused a significant difference among the observer. This study aims to develop the discriminant function for gender prediction in a Surabaya-Indonesia population age ranges 15-25-year-olds by using a panoramic radiograph. This research used 273 panoramic radiographs consisted of 129 male panoramic radiographs and 144 female panoramic radiographs. The researchers measured 11 parameters of the jaw such as two gonial angles, two mandibular ramus heights, two mandibular ramus widths, two mandibular corpus lengths, two nasal line maxilla, and anterior mandibular corpus heights. The researchers analyzed the data by using the discriminant analysis of the IBM SPSS statistic 24.
\end{abstract}

Results. the result of our study shows there were significant differences in the jaw morphometry between males and females, except the mandibular ramus widths. The jaw size in males was larger than that of the female. The biggest dimorphism variables based on the Wilks lambda value were gonial angles, mandibular ramus heights, mandibular corpus lengths, and nasal lines. While the smallest dimorphism variables were mandibular ramus widths. The accuracy of discriminant analysis for each variable ranges from $47.3 \%$ to $93.8 \%$.

Conclusion. This preliminary study in Surabaya-Indonesia population age ranges 15-25-year-olds by using panoramic radiograph shows the highest accuracy of gender prediction by using discriminant function was obtained from the combination of the nine jaw parameters.

Key Words: gender, mandibular, maxilla, panoramic radiograph

\section{INTRODUCTION}

Gender estimation is a key component of the individual biological profile to achieve the goal of forensic antropology $y^{1}$ Gender identification by using skeletal identification is an important tool in forensic, medico-legal, bio-arkeology, and anthropology. The methods of gender determination may vary depending on the available bones. ${ }^{1,2}$ Generally, the methods of gender estimation were grouped into two categories i.e. the method that focused on size and robusticity of anatomy feature

Corresponding author: Eha Renwi Astuti, DDS, MSc, PhD, OMR Department of Dental Maxillofacial Radiology Faculty of Dental Medicine Universitas Airlangga Jl. Mayjen Prof. Dr. Moestopo No.47, Pacar Kembang, Tambaksari, Surabaya City, East Java Indonesia 60132 Email: eha-r-a@fkg.unair.ac.id and the methods that involve the evaluation of the pelvis feature related to the female child-bearing functions. ${ }^{2,3}$ Based on Indonesian National Board for Disaster Management data, Indonesia is a disaster susceptible country; during 2018 there were 1999 mass disasters in Indonesia such as volcano eruption, tsunami, earthquake, and air-craft crashes. ${ }^{3}$ In this case, we found a lot of victims with incomplete bones. ${ }^{4}$ 
The accuracy of gender determination depends on the number of bone fragments and available parts of skeletons. The skull, pelvis, and femora are the most useful anatomy for radiological gender determination. Korgman stated that the gender determination accuracy of complete skeletal bone was $100 \%$, gender determination by using pelvis bone was $95 \%$, gender determination by using the skull was $90 \%$, gender determination by using pelvis bone and skull was $98 \%$, and gender determination by using long bones was $80 \%{ }^{5}$

When the entire skeletons are not available, the skull can be an accurate gender identification tool. ${ }^{5,6}$ The skull is the most dimorphic bones after the pelvis. In case the skull was not complete either, mandibular plays an important role in gender determination due to dimorphism of mandibular. In addition, mandibular is the largest and the strongest bone in the skull. Mandibular dimorphisms vary depending on races, ages, and masticatory muscle activities. 3,6,7

There were several studies about gender determination based on mandibular shape and morphometry in puberty samples; the results showed that pre-pubertal mandibular dimensions were not consistent. ${ }^{8,9}$ Conquerell et al. had stated that mandibular dimorphism changed during the development. Gender determination by using mandibular morphometric could not be detected at ages ranged 4-14 years old because there were different growths and development patterns between males and females. The mandibular shape dimorphism could be used on post-pubertal gender determination. ${ }^{9}$

The changes in mandibular shape and size can be observed by using a radiograph series. Radiography can assist in giving accurate dimensions for which certain formulae can be applied for gender determination. ${ }^{10}$ There have been several studies representing that it is proven that a panoramic radiograph can be used to evaluate the jaw morphometric. Dental practitioners usually use a panoramic radiograph to evaluate vital structures of the jaw, to evaluate jaw morphology as soon as the ages change in the different genders, and it represents the bilateral anatomy of the jaw. ${ }^{10,11,12}$

Traditional morphological methods depended on the anthropologist subjectivity understanding in sexual dimorphism of the jaw, it caused a significant difference among the observers. ${ }^{13}$ Therefore; we needed to devise the reliably discriminant analytical methods for dimorphic fragment bones. Discriminant function analysis is increasingly used to determine sex from the skeleton, but it's limited to a specific population. This present study was undertaken to develop the discriminant function for gender prediction in a SurabayaIndonesia population age ranges $15-25$ years by using a panoramic radiograph and to determine the most dimorphic parameter of the jaw taken on the panoramic radiograph.

\section{MATERIALS AND METHODS}

This research method uses an analytical cross-sectional design. The researcher conducted the study from December
2018 until February 2019, the location of the research was at oral maxillofacial radiology department dental hospital at Airlangga University, Surabaya, Indonesia. This research obtained approval from the Ethics Committee Faculty of Dental Medicine, Airlangga University, Surabaya (no: 602/ HRECC.FODM/IX/2019).

The research population was panoramic radiographs taken from patients aged 15 to 25 years who came to the dental radiology installation dental hospital Airlangga University, Surabaya, Indonesia in January 2018-December 2018. The panoramic radiographs were taken from Instrumentarium OP 200D-1 Digital Panoramic and Cephalometric System (70 kVp, $8 \mathrm{~mA}, 12 \mathrm{~s})$.

The samples included in this study were good quality panoramic radiographs. Exclusion criteria used in this study were panoramic radiographs with growth abnormalities of the jaw, the mandibular panoramic radiographs with pathological lesions, such as cysts or tumors, and the panoramic radiographs with a fractured jaw.

This research used 273 panoramic radiographs consisted of 129 male panoramic radiographs and 144 female panoramic radiographs. The panoramic radiographs were evaluated by two radiologists. We used IG Measure software to measure the parameter on panoramic radiographs (Figure 1). The images were evaluated by the same observer for a second time after two weeks for intra-examiner calibration and to determine the reliability of the jaw measurements. The radiologist took the measurement twice and used the average result from the measurement as the final result. The intra- and inter-observer agreement was analyzed by using Cohen-Kappa analysis of the IBM SPSS statistic 24. A radiologist did the measurement on both the left and right sides of the jaws. All of the variable measurements except the anterior mandibular corpus height measurement were obtained on both right and left side, assuming that the perfect bilateral symmetry human face was rarely found. The researchers measured some variables:

1. Gonial angles: the angles measured from the intersection of inferior mandibular corpus and posterior mandibular ramus borders.

2. Mandibular ramus height: The distance from Condylion point (Co: the most superior point of condyle) to Gonion point (Go: the most inferior and posterior point of the angle of the mandible).

3. Mandibular ramus widths: the smallest anteriorposterior diameter of the mandibular ramus.

4. Mandibular corpus length: the distance from Gonion point to Menton point (Me: the lowest point on the mandibular symphisis on the mid-sagittal line).

5. Anterior mandibular corpus height: the distance from alveolar crest to mandibular inferior border in midsagittal line.

6. Nasal line maxilla: the distance from anterior nasal spine point to pterigomaxilla. 


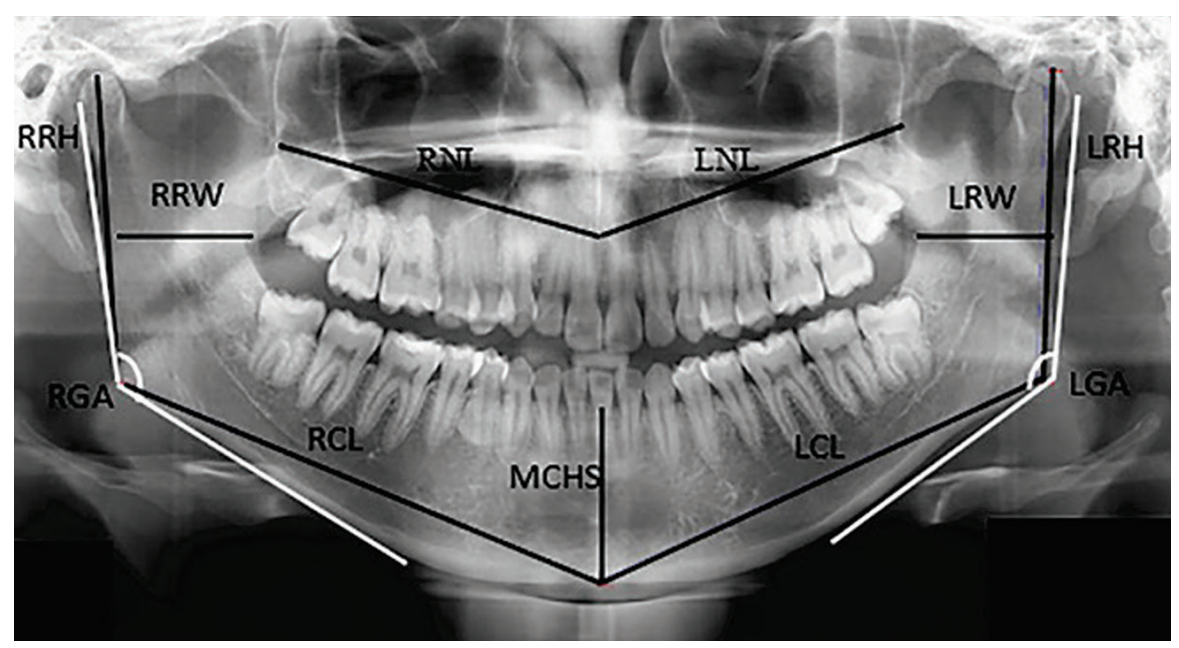

Figure 1. Image shows the measurement of 11 parameters on panoramic radiograph.

The researchers analyzed the data by using the discriminant analysis of the IBM SPSS statistic 24. The aims of the discriminant analysis were:

a. To differentiate male and female groups' determinant based on the categories

b. To test the significant differences of the jaw morphometric by using discriminant analysis

c. To determine the jaw parameters which make the significant differences between male and female groups by using discriminant analysis.

\section{RESULT}

The inter- and intra-observer analyses revealed that all variables presented good agreement with kappa coefficients greater than 0.72 . Figures 2 and 3 show the average values of the jaw parameters on male and female groups. The research result in Figures 2 and 3 represents that the mandibular and maxilla size in males and larger than those of females.
Based on Table 1 (Wilks lambda test) shows that the $P$-value is $0.000<0.05$, it means there is a significant difference between male and female jaw morphometric, except on the mandibular ramus width ( $P$-value: 0.585$)$. The biggest dimorphism variable based on the Wilks lambda value was gonial angles, mandibular ramus heights, mandibular corpus lengths, and nasal lines. While the smallest dimorphism variable was mandibular ramus width.

Table 2 shows the discriminant analysis results, such as discriminant function and cut-off values. The discriminant functions were formulated by multiplying the variable coefficients. The gender prediction can be determined from the calculation results of the discriminant function and compared to the cut-off values. If the discriminant values were greater than the cut-off points, they indicate the male groups. If the discriminant values were less than the cut-off points, they indicate the female groups.

Table 3 presents the prediction percentage of gender determination based on each discriminant function from the Surabaya population sample for the right and the left

Table 1. Wilks lambda score between males and females

\begin{tabular}{|c|c|c|c|c|}
\hline \multirow{2}{*}{ Variable } & \multicolumn{2}{|c|}{ Gender } & \multirow{2}{*}{ Wilks lambda score } & \multirow{2}{*}{ Sig } \\
\hline & Male & Female & & \\
\hline Right gonial angle (RGA) & 129 & 144 & 0.916 & 0 \\
\hline Right ramus height (RRH) & 129 & 144 & 0.295 & 0 \\
\hline Right ramus width (RRW) & 129 & 144 & 0.999 & 0.585 \\
\hline Right corpus length (RCL) & 129 & 144 & 0.821 & 0 \\
\hline Left gonial angle (LGA) & 129 & 144 & 0.944 & 0 \\
\hline Left ramus height (LRH) & 129 & 144 & 0.304 & 0 \\
\hline Left ramus width (LRW) & 129 & 144 & 0.984 & 0.039 \\
\hline Left corpus length (LCL) & 129 & 144 & 0.830 & 0 \\
\hline Mandibular corpus height in symphysis region (MCHS) & 129 & 144 & 0.739 & 0 \\
\hline Right Nasal Line (RNL) & 129 & 144 & 0.862 & 0 \\
\hline Left Nasal Line (LNL) & 129 & 144 & 0.894 & 0 \\
\hline
\end{tabular}




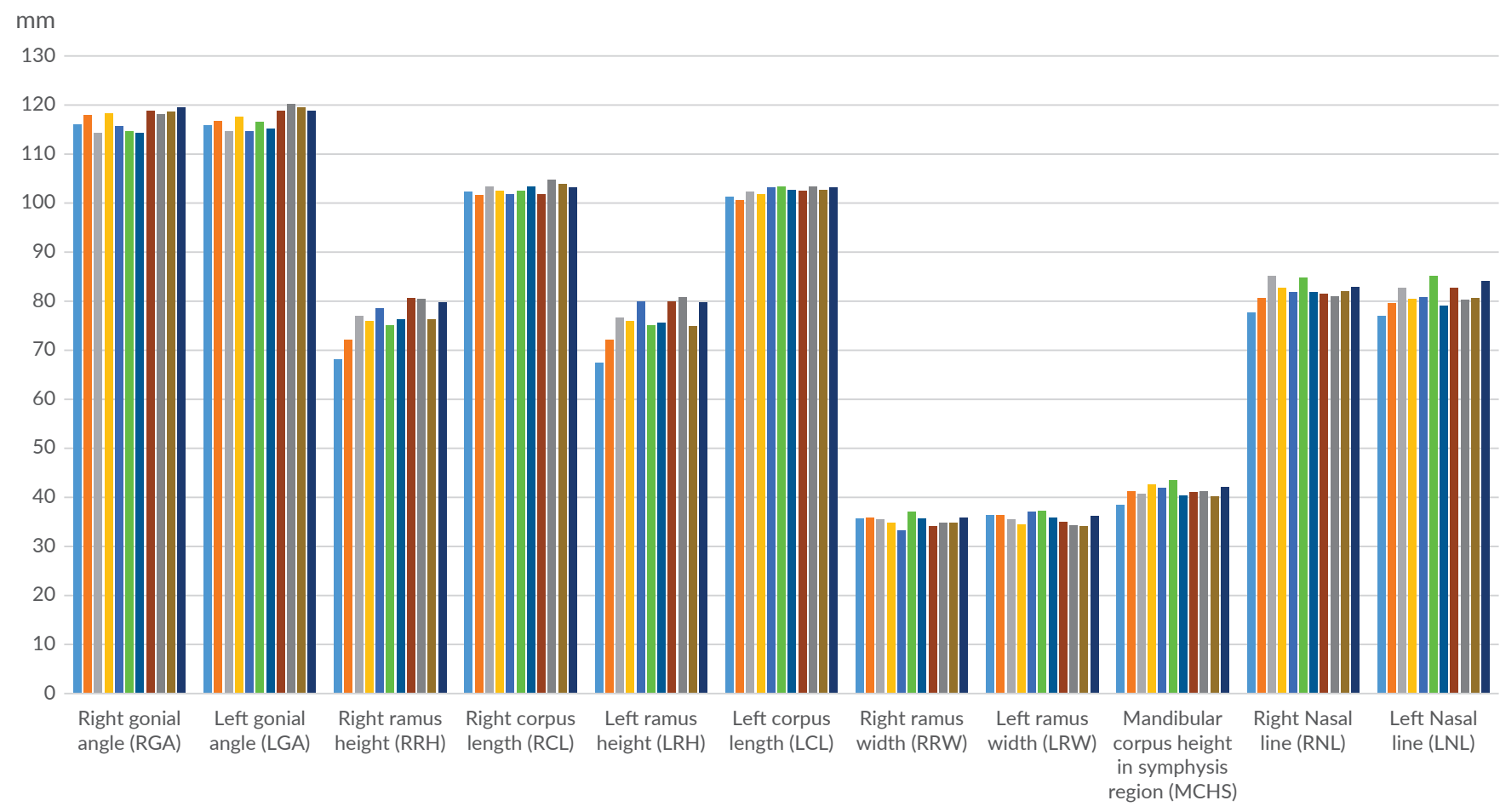

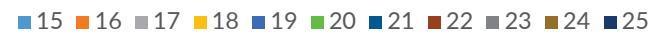

Figure 2. The average values for the 11 parameters in male age range 15-25 year olds.

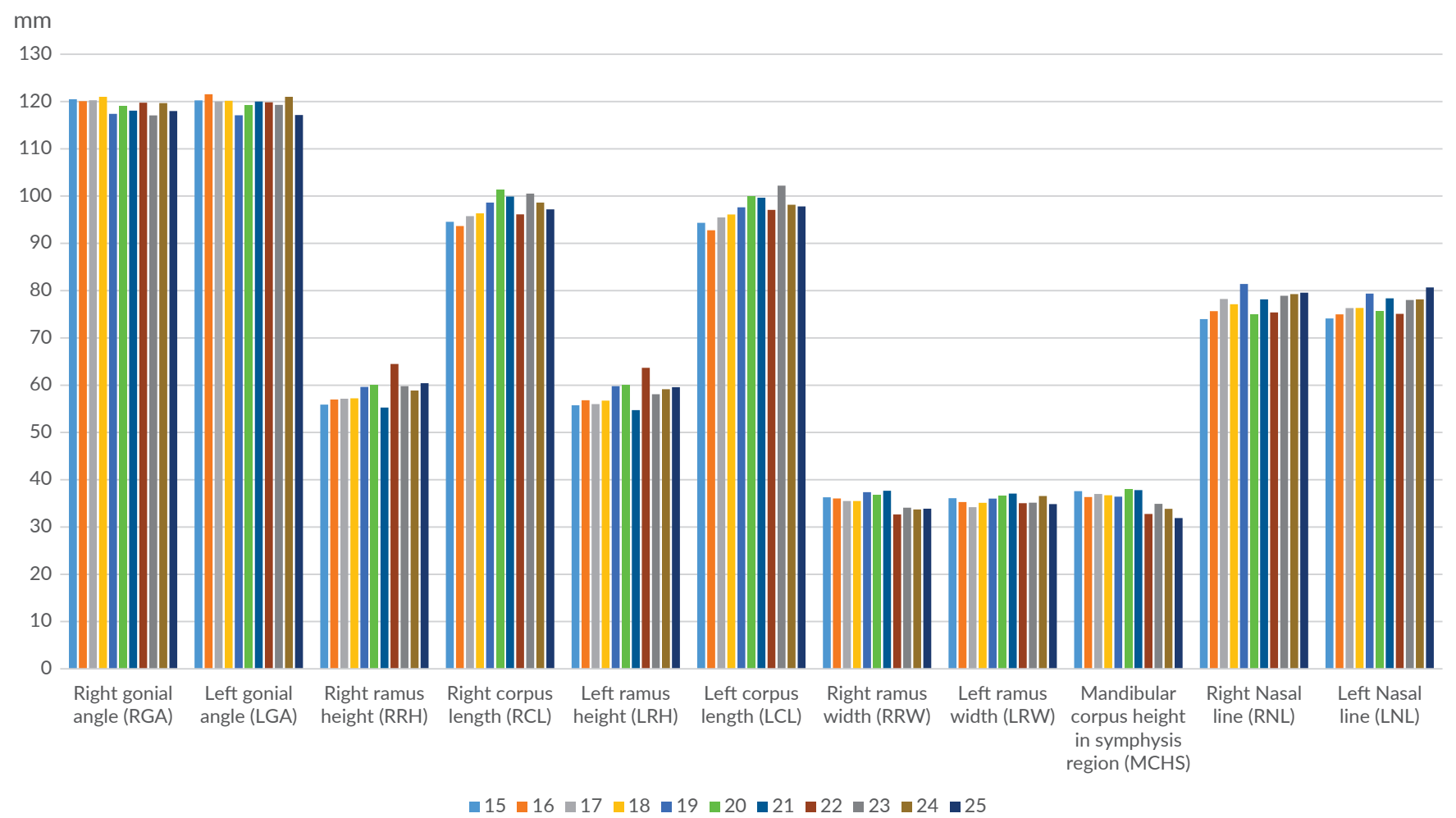

Figure 3 . The average values for the 11 parameters female age range 15-25 year olds. 
Table 2. Discriminant analysis

Table 2a. Discriminant function by using the right nasal line and the mandibular right side parameters

\begin{tabular}{|c|c|c|c|c|}
\hline Variable & Function coefficient & Discriminant Function & Cut off point & Determination \\
\hline $\begin{array}{l}\text { Right gonial angle (RGL) } \\
\text { Right ramus height (RRH) } \\
\text { Right ramus width (RRW) } \\
\text { Right corpus length (RCL) } \\
\text { Mandibular corpus height in } \\
\text { symphysis region (MCHS) } \\
\text { Right Nasal Line (RNL) } \\
\end{array}$ & $\begin{array}{c}-0.008 \\
0.158 \\
-0.045 \\
0.041 \\
0.028 \\
0.005 \\
\text { Constanta: }-13.64\end{array}$ & $\begin{aligned} \mathrm{Z}= & -13.640-(0.008 \mathrm{RGL})+ \\
& 0.158 \mathrm{RRH}-0.45 \mathrm{RRW}+ \\
& 0.041 \mathrm{RCL}+0.028 \mathrm{MCHS} \\
& +0.005 \mathrm{RNL}\end{aligned}$ & -0.00077 & $\begin{array}{l}\text { If Zscore }>-0.00077 \text { indicates male } \\
\text { If Zscore }<-0.00077 \text { indicates female }\end{array}$ \\
\hline
\end{tabular}

Table 2b. Discriminant function by using the left nasal line and the mandibular left side parameters

\begin{tabular}{|c|c|c|c|c|}
\hline Variable & Function coefficient & Discriminant Function & Cut off point & Determination \\
\hline $\begin{array}{l}\text { Left Gonial Angle (LGA) } \\
\text { Left ramus height (LRH) } \\
\text { Left ramus width (LRW) } \\
\text { Left corpus length (LCL) } \\
\text { Mandibular corpus height in } \\
\text { symphysis region (MCHS) } \\
\text { Left Nasal Line (LNL) }\end{array}$ & $\begin{array}{c}-0.005 \\
0.157 \\
-0.039 \\
0.044 \\
0.033 \\
\\
-0.015 \\
\text { Constanta: }-13.011\end{array}$ & $\begin{aligned} Z= & -13.011-(0.008 \mathrm{SGKi})+ \\
& 0.157 \mathrm{TRKi}-0.39 \mathrm{LRKi}+ \\
& 0.44 \mathrm{LKKi}+0.033 \mathrm{TM}- \\
& 0.015 \mathrm{NLKi}\end{aligned}$ & -0.00044 & $\begin{array}{l}\text { If Zscore }>-0.00044 \text { indicates male } \\
\text { If Zscore }<-0.00044 \text { indicates female }\end{array}$ \\
\hline
\end{tabular}

Table 2c. Discriminant function by using the mandibular right side and the mandibular left side

\begin{tabular}{|c|c|c|c|c|}
\hline Variable & Function coefficient & Discriminant Function & Cut off point & Determination \\
\hline $\begin{array}{l}\text { Right gonial angle (RGA) } \\
\text { ght ramus height (RRH) } \\
\text { Right ramus width (RRW) } \\
\text { Right corpus length (RCL) } \\
\text { Left gonial angle (LGA) } \\
\text { Left ramus height (LRH) } \\
\text { Left ramus width (LRW) } \\
\text { Left corpus length (LCL) } \\
\text { Mandibular corpus height in } \\
\text { symphysis region (MCHS) }\end{array}$ & $\begin{array}{r}0.008 \\
0.097 \\
-0.047 \\
0.032 \\
-0.016 \\
0.067 \\
-0.001 \\
0.01 \\
0.026 \\
\text { Constanta: }-13.52\end{array}$ & $\begin{aligned} \mathrm{Z}= & -13.520-(0.008 \mathrm{RGA})+ \\
& 0.097 \mathrm{RRH}-0.47 \mathrm{RRW}+ \\
& 0.32 \mathrm{RCL}-0.016 \mathrm{LGA}+ \\
& 0.067 \mathrm{LRH}-0.001 \mathrm{LRW}+ \\
& 0.010 \mathrm{LCL}+0.026 \mathrm{MCHS}\end{aligned}$ & -0.000165 & $\begin{array}{l}\text { If Zscore }>-0.000165 \text { indicates male } \\
\text { If Zscore }<-0.000165 \text { indicates female }\end{array}$ \\
\hline
\end{tabular}

Table 2d. Discriminant function by using gonial angle and mandibular corpus parameters mandibular left and right

\begin{tabular}{|c|c|c|c|c|}
\hline Variable & Function coefficient & Discriminant Function & Cut off point & Determination \\
\hline $\begin{array}{l}\text { Right gonial angle (RGA) } \\
\text { Right corpus length (RGL) } \\
\text { Left gonial angle (LGA) } \\
\text { Left corpus length (LCL) } \\
\text { Mandibular corpus height in } \\
\text { symphysis region (MCHS) }\end{array}$ & $\begin{array}{r}-0.015 \\
0.045 \\
-0.058 \\
0.039 \\
0.197 \\
\text { Constanta: }-7.244\end{array}$ & $\begin{aligned} Z= & -7.244-(0.015 R G A)+ \\
& 0.45 R G L-0.058 L G A+ \\
& 0.039 L C L+0.197 M C H S\end{aligned}$ & -0.00011 & $\begin{array}{l}\text { If Zscore }>-0.00011 \text { indicates male } \\
\text { If Zscore }<-0.00011 \text { indicates female }\end{array}$ \\
\hline
\end{tabular}

Table 2e. Discriminant function by using mandibular ramus height and corpus length parameters

\begin{tabular}{|c|c|c|c|c|}
\hline Variable & Function coefficient & Discriminant Function & Cut off point & Determination \\
\hline $\begin{array}{l}\text { Right ramus height (RRH) } \\
\text { Right corpus length (RCL) } \\
\text { Left ramus height (LRH) } \\
\text { Left corpus length (LCL) } \\
\text { Mandibular corpus height in } \\
\text { symphysis region (MCHS) }\end{array}$ & $\begin{array}{c}0.101 \\
0.011 \\
0.065 \\
0.024 \\
0.017 \\
\end{array}$ & $\begin{aligned} \mathrm{Z}= & -15.235+0.101 \mathrm{RRH}+ \\
& 0.011 \mathrm{RCL}+0.065 \mathrm{LRH}+ \\
& 0.024 \mathrm{LCL}+0.17 \mathrm{MCHS}\end{aligned}$ & -0.00044 & $\begin{array}{l}\text { If Zscore }>-0.00044 \text { indicates male } \\
\text { If Zscore }<-0.00044 \text { indicates female }\end{array}$ \\
\hline
\end{tabular}


Table 3. The percentage of correct classifications for the discriminant functions

\begin{tabular}{|c|c|c|c|c|c|}
\hline \multirow{2}{*}{ Discriminant Function } & \multicolumn{2}{|c|}{ Total Male Sample } & \multicolumn{2}{|c|}{ Total Female Sample } & \multirow{2}{*}{$\begin{array}{l}\text { Correct } \\
\text { Classification \% }\end{array}$} \\
\hline & $\mathrm{N}=129$ & $\%$ & $\mathrm{~N}=144$ & $\%$ & \\
\hline $\begin{aligned} Z= & -13.640-(0.008 R G A)+0.158 R R H-0.45 R R W+0.041 R C L+0.028 M C H S \\
& +0.005 R N L\end{aligned}$ & 121 & $93.80 \%$ & 137 & $95.10 \%$ & $94.50 \%$ \\
\hline $\begin{aligned} Z= & -13.011-(0.008 L G A)+0.157 \text { LRH }-0.39 L R K i+0.44 L K K i+0.033 T M- \\
& 0.015 \text { LNL }\end{aligned}$ & 118 & $91.50 \%$ & 135 & $93.80 \%$ & $92.70 \%$ \\
\hline $\begin{aligned} Z= & -13.520-(0.008 R G A)+0.097 R R H-0.47 R R W+0.32 R C L-0.016 L G A+ \\
& 0.067 L R H-0.001 L R W+0.010 L C L+0.026 \mathrm{MCHS}\end{aligned}$ & 123 & $95.30 \%$ & 137 & $95.10 \%$ & $95.20 \%$ \\
\hline$Z=-7.244-(0.015 R G A)+0.45 R G L-0.058 L G A+0.039 L C L+0.197 M C H S$ & 104 & $80.60 \%$ & 115 & $79.90 \%$ & $80.20 \%$ \\
\hline$Z=-15.235+0.101 R R H+0.011 R C L+0.065 L R H+0.024 L C L+0.17 M C H S$ & 123 & $95.30 \%$ & 136 & $94.40 \%$ & $94.90 \%$ \\
\hline
\end{tabular}

Table 4. The discriminant function and the accuracy of the discriminant function each variable

\begin{tabular}{|c|c|c|c|c|}
\hline Variable & Unstandardized coefficient & Centroid & Cut off point & Accuracy \\
\hline RGA & $\begin{array}{l}0.196 \\
\text { Constanta }=-23.230\end{array}$ & $\begin{array}{l}\text { male: }-0.318 \\
\text { female: } 0.285\end{array}$ & 0.000066 & $63.00 \%$ \\
\hline LGA & $\begin{array}{l}0.193 \\
\text { Constanta }=-22.904\end{array}$ & $\begin{array}{l}\text { male: }-0.256 \\
\text { female: } 0.229\end{array}$ & -0.00018 & $60.40 \%$ \\
\hline RRH & $\begin{array}{l}0.173 \\
\text { Constanta }=-11.579\end{array}$ & $\begin{array}{l}\text { male: } 1.627 \\
\text { female: }-1.458\end{array}$ & -0.00025 & $93.80 \%$ \\
\hline LRH & $\begin{array}{l}0.167 \\
\text { Constanta }=-11.129\end{array}$ & $\begin{array}{l}\text { male: } 1.594 \\
\text { female: }-1.428\end{array}$ & -0.000021 & $92.30 \%$ \\
\hline RRW & $\begin{array}{l}0.266 \\
\text { Constanta }=-9.386\end{array}$ & $\begin{array}{l}\text { male: } 0.035 \\
\text { female: }-0.031\end{array}$ & 0.00019 & $47.30 \%$ \\
\hline LRW & $\begin{array}{l}0.266 \\
\text { Constanta }=-9.433\end{array}$ & $\begin{array}{l}\text { male: } 0.133 \\
\text { female: }-0.119\end{array}$ & 0.000077 & $49.50 \%$ \\
\hline $\mathrm{RCL}$ & $\begin{array}{l}0.176 \\
\text { Constanta }=-17.576\end{array}$ & $\begin{array}{l}\text { male: } 0.491 \\
\text { female: }-0.440\end{array}$ & -0.000077 & $68.10 \%$ \\
\hline LCL & $\begin{array}{l}0.175 \\
\text { Constanta }=-17.429\end{array}$ & $\begin{array}{l}\text { male: } 0.476 \\
\text { female: }-0.427\end{array}$ & -0.00031 & $66.30 \%$ \\
\hline $\mathrm{MCHS}$ & $\begin{array}{l}0.253 \\
\text { Constanta }=-9.837\end{array}$ & $\begin{array}{l}\text { male: } 0.626 \\
\text { female: }-0.560\end{array}$ & 0.00042 & $73.30 \%$ \\
\hline RNL & $\begin{array}{l}0.159 \\
\text { Constanta }=-12.696\end{array}$ & $\begin{array}{l}\text { male: } 0.421 \\
\text { female: }-0.378\end{array}$ & -0.00045 & $65.90 \%$ \\
\hline LNL & $\begin{array}{l}0.163 \\
\text { Constanta }=-12.861\end{array}$ & $\begin{array}{l}\text { male: } 0.362 \\
\text { female: }-0.324\end{array}$ & 0.00015 & $64.80 \%$ \\
\hline
\end{tabular}

side. It shows that the accuracies of discriminant function varied depending on the various variables. We measured the right side and the left side of the jaw to detect any differences in classification accuracy. The accuracies of discriminant function on the left side (92.7\%) are lower than on the right side (94.5\%). The accuracies range from $80.20 \%$ to $95.20 \%$. The combination of the mandibular right and left side has the highest accuracies in the discriminant analysis (95.2\%).

Table 4 presents all of the parameter functions and the gender determination accuracies by using each parameter. The accuracy for each variable ranged from $47.3 \%$ to 93.8\%. Right ramus height has the highest accuracy in the discriminant analysis (93.8\%). The lowest accuracy was the right ramus width (47.3\%). The right-side measurements exhibited slightly better performance compared with the left side measurement.

\section{DISCUSSION}

Gender dimorphism referred to the difference in sizes, shapes, and appearances between male and female anatomy. Recently, there were many gender dimorphism studies by using metric parameters with reliable results. ${ }^{11,13,14,15}$ Therefore, we can apply gender dimorphism on the gender determination skeletons by using discriminant analysis. The discriminant function analysis in our studies is used to quantify the assessment of the jaw morphology.

The mandibular and maxilla are the bones that provide information about genders. Both mandibular and maxilla have different morphology changes between males and females. Each of the 11 variables measured on mandibular and maxilla of the Surabaya population showed statistically significant on gender differences between sexes, except the mandibular ramus widths. Our results suggest that the 
mandibular and maxilla size in males is greater than those of females. Therefore; we conclude that there is a gender dimorphism of the jaw in our population. Our result studies are the same as the studies done by Datta et al., Dong et al., Laowansari et al., and Liu et al. ${ }^{16,17,18}$

Datta et al. studies presented 12 parameters of the mandibular such as gonial angle, bigonial width, ramus height, bicondylar breadth, mandibular length, length of the lower jaw, mandibular index, body thickness, coronoid height, bimental breadth, symphyseal height, and body height were the useful tools for gender determination. It was because all the other parameters showed significant gender differentiation with high accuracies. ${ }^{16}$

Dong et al. studies in Han Chinese population found there was a significant sexual dimorphism in the examined ten parameters of the mandibular (bi-condylar breadth, bi-gonial breadth, bi-antegonial notch breadth, bi-mental foramina breadth, the distance between mental foramen and mandibular inferior border, maximum mandibular ramus breadth, maximum mandibular length, maximum mandibular ramus height, maximum mandibular body length, mandibular angle, and mental angle). The accuracies of sex determination between 61.1 and $81.8 \% .{ }^{17}$

Laowansari et al. result studies present that there were significant differences in maxilla size between males and females, the male maxilla was greater than that of females. ${ }^{18}$ The research done by Datta et al., Dong et al., and Liu et al. showed that the males mandibular were greater than that of females. ${ }^{16,17,19}$ The size differences between males and females were caused by different bone remodeling patterns. It has been found that many factors influenced the bone remodeling patterns such as genetics, races, muscle mass, masticatory muscle activities, gender hormone, and socio-economy environment. ${ }^{20,21}$ The male bone growth mainly occurs in periosteal, whereas the female bone growth mainly occurs in the endosteal, it causes the bone volume, and the bone sizes in males are greater than those of females. ${ }^{22,23}$

Based on Figures 2 and 3, our study results in the 15-25 years old samples, ramus height shows the greatest univariate gender dimorphism followed by corpus height in the symphysis region. The least univariate gender dimorphism was the ramus width. The overall prediction rate using all nine variables was $95.2 \%$. When we removed nasal lines and the ramus widths, the accuracy was $80.20 \%$. When we combined mandibular ramus height, mandibular corpus length, and mandibular corpus height the accuracy was adequate (94.90\%). It means that mandibular ramus height and mandibular corpus height in the symphysis region are a good indicator of gender determination.

The mandibular showed gender dimorphism from an early stage of life. ${ }^{24}$ Nevertheless, mandibular gender dimorphism is reduced during childhood (between the ages of 4 and 14), and it becomes most prominent during adulthood. ${ }^{9}$ Several studies investigated the mandible to determine the gender in sub-adult samples, even though some researchers argue that the skull bones have limited value before puberty. ${ }^{25,26}$ Based on the Pillai TJ et al. studies in Tirupai-India, there are six parameters of the mandibular that could be used to identify the gender such as right mandibular ramus height, corpus mandibular thickness, the jaw arch, inter-incisive with, mandibular indexes, and gonial angles. Their studies showed that the accuracy of unknown mandibular bone to determine gender using their methods was $75 \% .{ }^{27}$ Wankhede et al. result studies showed that six of the ten mandibular variables which were examined such as bicondylar breadth, projection length of the corpus of mandible, symphyseal height, coronoid breadth of the lower jaw, the height of the mandibular corpus, and corpus thickness of the mandibular body showed the best gender dimorphism. They conclude that those six parameters of the mandibular could be used for gender determination in Central Indian population with an accuracy rate that varies from 81.7 to $85.4 \% .^{28}$

Loth et al. researched a non-metric method towards sub-adult population South Africa showed the different shapes in symphysis region and anterior mandibular corpus could be used to predict the gender, the accuracy was above $80 \% .{ }^{29}$ Based on Akhlagi et al. studies in subadult Iranian samples, the mandibular anthropometric parameters are not very helpful in sex determination below the age of 12 . However, if only the mandibular is available, symphysial height and mandibular bigonial breadth could be used to gender determination. In the 12-19 age group, the accuracy of symphysial height and bigonial breadth in the differentiation of gender was $69 \%$ and $86.2 \%$, respectively. ${ }^{30}$

Kharoshah et al. stated that the parameters of the mandibular which had significant differences between males and females were bicondylar widths, gonial angles, and mandibular ramus widths. The accuracy of gender determination by using this parameter was about $83.6 \%$ in males and $84.2 \%$ in females. On the contrary, our result studies presented that there were no significant differences between males' and females' ramus widths. The differences in the metric measurements indicated that the value may differ among the population depending upon the regional, geographic, environmental factors, genetics, and hormonal factor. ${ }^{31}$

In Saudi population aged ranging from 10-60 years old, Sandeepa et al. studied nine mandibular parameters and noted that mandibular ramus widths, mandibular corpus heights in molar region, coronoid height, condyle height, and mandibular corpus height in premolar region had the highest dimorphism value. While the lowest dimorphism values were gonial angles and bigonial widths. The average accuracy for gender determination by using discriminant function varied from $54.8 \%$ to $92.75 \% \%$. The highest accuracy value was obtained from the combination of 9 parameters (maximum ramus breadth, minimum ramus breadth, maximum condylar height, maximum ramus height, maximum coronoid height, gonial angle, bigonial width, body height in premolar area, body height in molar area). ${ }^{32}$ 
In 2019, Bertsatos et al. studied 194 mandibles of adult Greek aged ranging 19-99 years old. The research result showed that only five parameters of the mandible exhibited a cross-validated correct classification percentage over $75 \%$. These parameters concerned the right-side measurements: ramus height, maximum ramus height, coronoid height, coronion-gonion length, and maximum mandible length. Their study produced several suitable discriminant functions based on mandibular measurements that can be used for gender determination unidentified individuals in the Modern Greek population ${ }^{33}$

Lopez-Capp et al. did the studies towards the Brazilian population aged ranging 18-104 years old found that among the 21 parameters of the mandible analyzed, the greatest sexual dimorphism was the bigonial breadth, minimum ramus breadth right, left maximum ramus heights, mandibular length, and bicondylar breadth. The discriminant analysis revealed the accuracy varied from 49 to $79 \%$. The greatest accuracy was bigonial breadth (79\%), and the lowest accuracy was left body thickness at the mental foramen (49\%). ${ }^{34}$

Based on our research and the other researches towards different population we can say that the accuracy of discriminant analysis varies depending on the type of parameter, the amount of parameter, and the population variation. The limitation of our study is the small sample size used in this present study. Therefore, we suggest that for future researches, use larger samples and various populations to assess the effectiveness of this gender determination method.

\section{CONCLUSION}

This preliminary study in Surabaya-Indonesia population age ranges 15-25-year-olds by using a panoramic radiograph shows the highest accuracy of gender prediction by using discriminant function was obtained from the combination of the nine parameters. The ramus height is the greatest gender dimorphism, and the least gender dimorphism is ramus width. We hope that the derived discriminant function can be used as a reference for gender prediction in future researches, especially in dental forensic science.

\section{Statement of Authorship}

All authors participated in data collection and analysis, and approved the final version submitted.

\section{Author Disclosure}

All authors declared no conflicts of interest.

\section{Funding Source}

No funding support.

\section{REFERENCES}

1. Rowbothan SK, Anthropological estimation of sex, in: Soren Blau, Douglas H. Ubelaker (Eds.), Handbook of Forensic Anthropology and Archaeology, 2nd ed., Routledge. New York; 2016: p. 261-72.
2. Ubelaker DH, DeGaglia CM. Population variation in skeletal sexual dimorphism. Forensic Science International. 2017; 407: e1-7.

3. Krishan K, Chatterjee PM, Kanchan T, Kaur S, Baryah N, Singh RK. A review of sex estimation techniques during examination of skeletal remains in forensic anthropology casework. Forensic Science International. 2016; 265: 165.e1-8.

4. Data informasi bencana Indonesia. Badan Nasional Penanggulangan Bencana. [cited 2019 April 10]. Available from: https://bnbp.cloud/ dibi/tabel1a.

5. Reddy KSN, Murthy OP. The essentials of forensic medicine and toxicology. 33rd edition. New Delhi: Jaypee Brothers Medical Publishers; 2014. p.65.

6. Ogawa Y,Imaizumi K, Miyasaka S, Yoshino M. Discriminant functions for sex estimation of modern Japanese skulls. Journal of Forensic and Legal Medicine. 2013;20: 234-8.

7. Sharma M, Gorea RK, Gorea A, Abuderman A. A morphometric study of the human mandible in the Indian population for sex determination. Egyptian Journal of Forensic Sciences. 2016; 6: 165-9.

8. Indira AP, Markande A, David MP. Mandibular ramus: An indicator for gender determination - A digital radiographic study. J Forensic Dent Sci 2012;4:58-62.

9. Coquerelle M, Bookstein FL, Braga J, Halazonetis DJ, Weber GW, Mitteroecker P. Genderual Dimorphism of the human mandible and its association with dental development. American Journal of Anthropology 2011; 145:192-202.

10. Nadendla LK, Paramkusam G, Pokala A, Devulapalli RV. Identification of gender using radiomorphometric measurements of canine by discriminant function analysis. Indian J Dent Res. 2016;27:27-31.

11. Rani A, Kanjani V, Kanjani D, Annigeri RG. Morphometric assessment of mental foramen for gender prediction using panoramic radiographs in the West Bengal population - A retrospective digital study. Journal of Advanced Clinical \& Research Insights. 2019; 6: 63-6.

12. Kumar SB, Deepthi.B C. A Digital Radiographic Study for Gender Prediction Using Mandibular Indices. International Journal of Science and Research (IJSR). 2016; 5(5): 1490-3.

13. Leversha J,McKeough G, Myrteza A,Skjellrup-Wakefiled H,Welsh J, Sholapurkar A. Age and gender correlation of gonial angle, ramus height and bigonial width in dentate subjects in a dental school in Far North Queensland. J Clin Exp Dent. 2016; 8(1): e49-54.

14. Santos LV, Galo R, da Silva RHA1. Gender evaluation in human beings by occlusal radiographs. Braz J Oral Sci. 2015; 14 (1): 23-6.

15. Lopez TT, Crosato EM, Benedicto EN, de Paiva LAS, Silva DCB, Biazevic MGH. Accuracy of mandibular measurements of sexual dimorphism using stabilizer equipment. Braz. Oral Res. 2017;31: 1-11.

16. Datta A, Siddappa SC, Gowda VK, Channabasappa SR, Shivalingappa $\mathrm{SBB}$, Srijith, Dey D. A study of gender determination from human mandible using various morphometrical parameters. Indian Journal of Forensic and Community Medicine 2015;2(3):158-66.

17. Dong H, Deng M, Wang WP, Zhang J, Mua J, Zhu G. Sexual dimorphism of the mandible in a contemporary Chinese Han population. Forensic Science International. 2015;255: 9-15

18. Laowansia U, Behrents RG, Araujo E, Oliver DR, Buschang PH. Maxillary growth and maturation during infancy and early childhood. Angle Orthodontist 2013; 83 (4): 563-71.

19. Liu YP, Behrentsb RG, Buschang PH. Mandibular growth, remodeling, and maturation during infancy and early childhood. Angle Orthodontist 2010;46(1): 33-7.

20. Shim KS. Pubertal growth and epiphyseal fusion. Annals of Pediatric Endocrinology and Metabolism 2015;20: 8-12

21. Soliman A, De Sanctis V, Elalaily R, Bedair S. Advances in pubertal growth and factors influencing it: Can we increase pubertal growth? Indian Journal of Endocrinology Metabolism 2014; 18(1): S53-62.

22. Lang TF. The Bone muscle relationship in men and women. Journal of Osteoporosis.2011:1-4.

23. Litsas G. Growth hormone and craniofacial tissue: an update. The Open Dentistry Journal.2015; 9: 1-8.

24. Kano T, Oritani S, Michiue T, Ishikawa T, Hishmat AM, Sogawa N et al. Postmortem CT morphometry with a proposal of novel parameters for sex discrimination of the mandible using Japanese adult data. Leg Med (Tokyo). 2015. tps://doi.org/10.1016/j.legalmed.2014.12.009 
25. Franklin D, Oxnard CE, O'Higgins P, Dadour I. Sexual dimorphism in the subadult mandible: quantification using geometric morphometrics. J Forensic Sci 2007;52:6-10.

26. Saukko P, Knight B. Knight's forensic pathology. 3rd ed. UK: Arnold; 2004: $98-135$.

27. Pillai TJ, Devi TS, Devi CKL. Studies on human mandible. IOSR Journal of dental and medical sciences 2014; 13(1): 8-15.

28. Wankhede KP, Bardale RV, Chaudhari GR, Kamdi NY. Determination of sex by discriminant function analysis of mandibles from a Central Indian population. J Forensic Dent Sci. 2015; 7(1): 37-43.

29. Loth SR, Henneberg M. ally dimorphic mandibular morphology in the first few years of life. Am J Phys Anthropol. 2001;115(2):179-86.

30. Akhlaghi M, Khalighi Z, Vasigh S. Yousefinejad V. Sex determination using mandibular anthropometric parameters in subadult Iranian samples. Journal of Forensic and Legal Medicine. 2014;22: 150-3.
31. Kharoshah MA, Al Madani OM, Galeb SS, Zaki MK, Abdel Fattah YA. Sexual dimorphism of the mandible in a modern Egyptian population. J Forensic Leg Med. 2010; 17(4): 213-5.

32. Sandeepa NC, Ganem AA, Alqhtani WA, Mousa YM, Abdullah EK, Alkhayri AH. Mandibular indices for gender prediction: A Retrospective radiographic study in Saudi population. J Dent Oral Health 2017;3 (9): 1-7.

33. Bertsatos A, Athanasopoulou K, Chovalopoulou ME. Estimating sex using discriminant analysis of mandibular measurements from a Modern Greek sample. Egyptian Journal of Forensic Sciences. 2019; 9(25): 1-12.

34. Lopez-Capp TT, Rynn C, Wilkinson C, de Paiva LAS, Crosato EM, Biazevic MGH. Discriminant analysis of mandibular measurements for the estimation of sex in a modern Brazilian sample. Int J Legal Med. 2018; 132:843-51.

\title{
Have you read the current trends in
} Medical and Health Research in the Philippines?

\section{Acta Medica Philippina The National Health Science Journal}

\author{
Access Online: www.actamedicaphilippina.upm.edu.ph
}

